\title{
Estado Novo, realismo e autoritarismo político
}

\author{
Luciano Aronne de Abreu*
}

\section{Introdução}

golpe de 10 de novembro de 1937 significou a implantação, no Brasil, de um projeto político autoritário que, desde a década anterior, era defendido por uma elite intelectual conservadora, em nome de um suposto realismo político nacional. Entre esses intelectuais, era lugar-comum a idéia de que, ao contrário da tradicional elite pensante do país, que teria seus olhos voltados para o exterior, deveríamos conhecer nossa própria sociedade, seus usos e costumes e, então, propor e executar as mudanças necessárias à nossa ordem política e social (BRESCIANI, 2005, p. 152). Além disso, eles também partilhavam a percepção de que tinham uma missão política a cumprir, apagando, assim, as fronteiras entre o homem de letras e o de ação (PECAULT, 1990, p. 21-24). A esse respeito, deve-se observar a coincidência de suas idéias com as de uma importante fração das elites políticas e militares, que, em nome da ordem e da unidade nacional, também defendia a implantação de um regime autoritário no país. Pode-se dizer, então, que, ao longo do Estado Novo, as mútuas interferências entre os campos político e intelectual constituíram-se em um importante fator de legitimação do regime, como o estudo do caso do Rio Grande do Sul propõe-se a demonstrar.

Luciano Aronne de Abreu é Doutor em História Latino-Americana pela Universidade do Vale do Rio dos Sinos (Unisinos) e Professor do Departamento de História e do Programa de Pós-Graduação em História da Pontifícia Universidade Católica do Rio Grande do Sul (PUC-RS). Endereço eletrônico: luciano.abreu@pucrs.br. 


\section{Estado autoritário: projeto intelectual e prática política}

Segundo Oliveira Vianna ${ }^{1}$, intelectual precursor e depois colaborador do Estado Novo, nenhuma de nossas constituições vingou porque não foram assentadas "sobre bases argamassadas com argila da nossa realidade viva, da nossa realidade social, da nossa realidade nacional", mas baseadas em modelos ingleses, franceses ou americanos (VIANNA, 1939, cap. XIV). Na opinião de Vianna, ao contrário dos espíritos pragmáticos, para quem a organização política e constitucional de um povo é um problema essencialmente prático, o chamado idealismo utópico ${ }^{2}$ seria a marca registrada de nossos legisladores, desde a Independência até a República. Ao invés desse utopismo, seria desejável que praticássemos no Brasil o chamado idealismo orgânico, que nasce da própria evolução orgânica da sociedade, como uma visão antecipada da evolução futura (idem, p. 11).

Quando, por exemplo, ocorreu a queda da Monarquia, segundo Vianna, embora os republicanos desejassem vagamente a República, não tinham um plano definido de organização política e administrativa do país. Daí se infere que a Constituição de 1891 foi uma obra de improviso, inspirada no modelo americano e em desacordo com a realidade nacional. Irônico, Vianna afirma que os republicanos "podiam ter-nos dado um belo edifício, sólido e perfeito, construído com a mais pura alvenaria nacional - e deram-nos um formidável barracão federativo, feito de improviso e a martelo, com sarrafos de filosofia positiva e vigamentos de

1 Intelectual conservador e discípulo de Alberto Torres, entre outras importantes obras Oliveira Vianna foi autor de Populações meridionais do Brasil (1952 [1920]), em que analisa, à luz de nosso passado colonial, as origens de nossos problemas contemporâneos e aponta a inadequação de nossas leis e instituições à nossa própria realidade. Essa obra serviu de referência para toda uma geração de intelectuais brasileiros, entre eles Francisco Campos, considerado um dos principais intelectuais do Estado Novo. Durante esse regime, Oliveira Vianna exerceu o cargo de Consultor Jurídico do Ministério do Trabalho.

2 Idealismo utópico seria, para Oliveira Vianna, todo e qualquer sistema doutrinário ou conjunto de aspirações políticas em desacordo com as condições reais e orgânicas da sociedade que pretende reger e dirigir. Já o idealismo orgânico, ao contrário, nasce da própria evolução orgânica da sociedade, como uma visão antecipada de uma evolução futura (cf. VIANNA, 1939). 
pinho americano" (idem, p. 58). Adiante, uma vez mais servindo-se da ironia, diz que os republicanos, ao contrário de Ihering, para quem "ninguém podia mover uma roda lendo apenas diante dela um estudo sobre a teoria do movimento", estavam convencidos justamente do oposto (idem, p. 81).

De uma forma ou de outra, pode-se dizer que essa é a questão central de toda a obra de Oliveira Vianna ${ }^{3}$, intelectual que atribui a causa de nossos problemas à inadequação de nossas leis e instituições à nossa própria realidade. Com base nessa constatação, algumas outras importantes questões colocam-se para o autor em seus diferentes estudos: compreender as causas do idealismo utópico no Brasil, conhecer a realidade brasileira por meio do estudo de seu passado e propor reformas que possibilitem adequar nossas leis e instituições à realidade nacional. Em relação à última, deve-se salientar que ela está diretamente ligada à já citada missão política dos intelectuais, que deverá ser analisada em suas relações com as idéias e práticas políticas autoritárias do Estado Novo.

A preocupação de Oliveira Vianna em compreender as causas de nosso idealismo utópico pode ser observada desde as obras $O$ idealismo na evolução política do Império e da República (1922) e 0 idealismo da Constituição (1924). Esta, não por coincidência, teve uma segunda edição em 1939, aumentada, na qual o autor refere-se ao Estado Novo como um exemplo de idealismo orgânico e de realismo político, legitimando-o em suas práticas políticas.

Segundo ele, de um modo geral, o idealismo utópico teria por causas as condições espirituais da primeira geração posterior à Independência, educada fora do Brasil e, portanto, alheia à nossa realidade; o fato de que a segunda geração, ainda que formada nas academias de São Paulo, Rio de Janeiro, Recife e Bahia, teve por mestres justamente os idealistas da primeira; e a coincidência entre nossa Independência e as revoluções liberais européias, que teriam influenciado nossos idealistas na organização da ordem legal do país. Em sua opinião, entretanto, o que mais espanta em nosso idealismo utópico não é sua cegueira à nossa realidade, mas sua

3 Essas questões podem ser encontradas também na obra de outros intelectuais conservadores, como, por exemplo, Torres (1978) e Campos (2001). 
duração de cem anos, pois, como já foi dito, esse mesmo idealismo teria se manifestado na época da elaboração da Constituição de 1891 e se mantido até 1937.

Nessas circunstâncias, Oliveira Vianna e outros intelectuais conservadores buscaram desvendar essa realidade dedicando-se ao estudo do passado nacional desde o período colonial, a fim de fazer um diagnóstico do presente e, com base nele, propor um modelo de organização política compatível com o que consideravam o Brasil real. Na obra Populações meridionais do Brasil (1952 [1920]), o autor destacou a importância da história na formação de um povo e, portanto, a necessidade de se estudar o passado para identificar o germe de nossas idéias atuais utilizando-se de métodos e instrumentos capazes de fazer a mais rigorosa e exata reconstituição possível desse passado. A princípio, retrocedendo seu estudo ao que ele chamava "século I da história nacional" identifica três diferentes histórias do Brasil, em virtude das determinações do meio físico e das pressões históricas e sociais sobre os elementos étnicos, que resultaram na formação de sociedades e tipos sociais específicos: no Norte, sociedade dos sertões, foi identificado o sertanejo; no Centro, sociedade das matas, o matuto; no Sul, sociedade dos pampas, o gaúcho.

Quanto ao meio físico, que teria moldado o tipo de sociedade formada nas diferentes regiões brasileiras, sua influência seria tão forte que os colonizadores portugueses pouco ou nada conseguiram no sentido de aqui estruturar uma sociedade unitária. Nas palavras do autor, o espaço brasileiro tem apenas uma dimensão - sua "extraordinária latitude" - e é marcado pela dispersão dos latifúndios, o que impediu o desenvolvimento do comércio, da indústria, das cidades e, ao mesmo tempo, simplificou as relações sociais e inviabilizou a organização da sociedade em classes. Em consequiência dessa "insolidariedade social" nascida do latifúndio, o Brasil não se teria constituído em uma verdadeira nação, cuja característica principal seria exatamente a solidariedade, fundada

4 Em vez de referir-se aos séculos XVI, XVII, XVIII e XIX, na obra Populações meridionais do Brasil, Vianna emprega uma periodização própria à história brasileira, que não corresponde à história de nenhuma outra nação, circunscrevendo o período colonial entre o século I e o século IV da história nacional. 
no interesse coletivo. Ao contrário, teria se desenvolvido entre os grandes fazendeiros (brancos de origem portuguesa) o que o autor define como "espírito de clã 5 ", que congregava também as camadas mais pobres (negros e mestiços) da população em busca de proteção contra a chamada "anarquia branca" 6 .

Com base nesse conhecimento do passado, em sua já citada obra 0 idealismo da Constituição (1924; 1939), Oliveira Vianna diz que os "sonhadores liberais e suas formosas construções políticas" falharam justamente por desconhecer que os clãs patriarcais são a base de toda a nossa estrutura social e política e que estão em nosso povo em um estágio muito elementar de integração social. Nesse sentido, segundo ele, constituem exceção os indivíduos que não estão preocupados apenas com os interesses particulares de seu clã ou partido político, que, por sua vez, nada mais é do que uma organização de interesse privado dos clãs (VIANNA, 1939, p. 65-69). Desse modo, Oliveira Vianna afirma que a "politicalha" é a forma como o espírito de clã manifesta-se em nossa vida política e administrativa: "Em cada brasileiro, mesmo o de idealismo mais elevado, há sempre um politiqueiro em latência, justamente porque há nele sempre um homem de clã” (idem, p. 69).

Esses mesmos argumentos serviram também para que Oliveira Vianna, na obra Problemas de política objetiva (1930), justificasse sua opinião de que as campanhas eleitorais modernas, base do modelo de democracia liberal, seriam inadequadas à realidade brasileira. Segundo ele, o fracasso dessas campanhas devia-se ao desconhecimento de nossos políticos das condições reais das organizações partidárias brasileiras:

5 O espírito de clã é a forma de manifestação social do povo brasileiro. Para se proteger da "anarquia branca", as pessoas mais pobres e fracas reúnemse aos fazendeiros, que as protegem. De acordo com Oliveira Vianna, o recrutamento militar é um importante agente de organização dos clãs, pois as pessoas buscam abrigo junto aos senhores de terra para escapar do serviço militar. Além disso, deve-se destacar a função tutelar dos clãs sobre a população pobre. $O$ espírito de clã constitui a força motriz de nossa história política (cf. VIANNA, 1952 [1920], cap. VIII).

6 Anarquia branca é a total ausência de proteção do Estado às populações mais pobres e fracas, situação de desamparo legal que leva essas pessoas a agruparem-se junto aos poderosos em busca de proteção. 
Os votos, que hão de caber a um dos candidatos, lhe serão dados com ou sem propaganda; os que devem sufragar o outro candidato a ele virão matematicamente, independentemente de qualquer exposição de programa. Esta atitude de refratariedade às sugestões da dialética doutrinária deriva deste fato particular ao nosso grupo nacional - de que a organização dos partidos se faz entre nós sob aquilo que em ciência social se costuma chamar - o 'sistema de clã”' (VIANNA, 1930, p. 130-131).

Em outras palavras, mais uma vez com base em seu conhecimento e sua interpretação do passado nacional, Oliveira Vianna defende a total falta de utilidade prática das campanhas eleitorais, que seriam puro idealismo utópico das elites liberais. Isso porque, de acordo com nossa realidade política, baseada no sistema de clãs eleitorais e partidários, o apoio dos eleitores estaria vinculado à pessoa dos chefes e não ao programa dos candidatos; nesse sentido, o vira-casaca seria aquele que muda de chefe e não aquele que muda de partido ou de idéia (idem, p. 131). Por isso, em sua opinião, deveríamos lutar para construir regimes convenientes e adequados ao nosso povo, em vez de adotarmos modelos belos e harmônicos. Ao contrário, portanto, do que acreditavam nossas elites políticas liberais, o real problema do Brasil não seria a liberdade política, baseada nos sistemas partidário e eleitoral, mas a falta de liberdade civil em uma sociedade dominada pelo sistema de clãs. A esse respeito, Oliveira Vianna dizia: "A verdade é que é possível existir um regime de perfeita liberdade civil sem que o povo tenha a menor parcela de liberdade política: e o governo do 'bom tirano' é uma prova disto. Mas, seria pueril conceber a existência de um regime de liberdade política sem a condição preliminar da liberdade civil" (idem, p. 80).

Assim, percebe-se de maneira muito clara que a proposta de ação política de Oliveira Vianna associa a adoção de um regime autoritário a um suposto realismo político, pela necessidade de subordinar os interesses dos indivíduos, clãs ou partidos ao interesse coletivo, o que seria expresso precisamente pela capacidade de obediência e disciplina, pelo culto do Estado e de sua autoridade (idem, p. 99). A esse respeito, o autor cita uma ilustrativa história de Rudiard Kipling sobre um grandioso desfile de tropas inglesas na Índia, que teria enchido de deslumbramento "as pupilas dos chefes bárbaros, 
vindos ali especialmente para assisti-lo". Na ocasião, tendo um desses chefes perguntado ao oficial inglês como seria possível realizar algo tão prodigioso, seguiu-se entre eles o seguinte diálogo:

- Muito simplesmente - foi dada uma ordem e esta foi obedecida. Mas os animais? São também inteligentes como os homens? - Não; eles obedecem, como os homens - explicou o oficial. O burro, o cavalo, o boi, o elefante, obedecem ao seu condutor; o condutor obedece ao sargento; o sargento obedece ao capitão; o capitão obedece ao major; o major obedece ao coronel; o coronel obedece ao brigadeiro, comandante de três regimentos; o brigadeiro obedece ao general, que obedece ao vice-rei, que, por seu turno, é servidor de S. M. a Imperatriz. O chefe bárbaro meditou um pouco e depois exclamou: Ah! Como seria bom se acontecesse a mesma coisa no Afeganistão! Lá, nós só fazemos o que está na nossa vontade - e não obedecemos a ninguém! - É por isso - acentuou o oficial inglês, olhando-o com sobranceria e torcendo maliciosamente os bigodes - é por isso que o vosso emir, a quem não obedeceis, é obrigado a vir aqui receber ordens do nosso vice-rei [...] (VIANNA, 1930, p. 100-102).

A moral da história, como se diz popularmente, é a de que obediência e autoridade são condições essenciais para a manutenção da ordem e o desenvolvimento de uma nação, de acordo com uma visão orgânica da sociedade ${ }^{7}$, na qual o Estado seria o cérebro e os demais órgãos - grupos, classes, profissões - desempenhariam diferentes funções, complementares entre si, formando um todo harmônico.

Em 1937, quando foi instituído o Estado Novo, esse regime seria visto por Oliveira Vianna como a consagração desses princípios, defendidos por nossos intelectuais conservadores desde a década anterior. Sobre isso, aliás, chegou a dizer: "Os princípios nele consagrados e as instituições nele admitidas [no regime estado-novista]

7 Bolívar Lamounier define o pensamento político conservador - formado a partir da I República - com base no conceito de ideologia de Estado, que legitima a autoridade do Estado como princípio tutelar da sociedade. Essa ideologia, entre outros princípios, fundamenta-se em uma visão orgânico-corporativa da sociedade, de acordo com a qual a harmonia do todo depende da diferenciação e complementaridade funcionais de seus órgãos, grupos, classes e profissões. A mudança da sociedade exigiria, segundo esse princípio, a existência de um cérebro ou poder coordenador - o Estado (cf. LAMOUNIER, 1985). 
não me surpreenderam. Por quase todos eles eu me vinha batendo na minha obra de publicista [...]" (VIANNA, 1939, p. 171).

De fato, pode-se dizer que essa tradição intelectual conservadora contribuiu para a construção, no Brasil, de uma prática política autoritária e a instituição do Estado Novo. No entanto, segundo Nilo Odália (1997, p. 141), Oliveira Vianna não chegou a desenvolver em sua obra uma teoria do Estado, mas, sim, uma concepção pragmática do papel que este deveria desempenhar, que poderia variar de acordo com a situação histórica. Nesse mesmo sentido, pode-se dizer, também, que não foi menos pragmático o uso que o regime fez desse pensamento (e do pensamento de outros intelectuais conservadores), a fim de legitimar suas práticas políticas.

Nesses termos, ao avaliar a situação histórica nacional nos anos imediatamente anteriores a 1937, Oliveira Vianna dizia que o Estado Novo foi uma reação ao espírito faccioso do parlamento, à esterilidade de sua ação legislativa e à ausência de preocupação dos partidos com os interesses coletivos, o que tornava a Câmara um centro de agitações estéreis. Esses mesmos argumentos e idéias foram utilizados por políticos e militares conservadores com o intuito de legitimar seu poder político autoritário, em detrimento do modelo liberal-democrático e federativo vigente até então.

Vários exemplos poderiam ilustrar o pragmatismo dessas formulações intelectuais e das práticas políticas a elas associadas. Tomemos como referência o caso do Rio Grande do Sul, em que sua tradicional polarização política, acirrada sobretudo a partir de 1936, serviu de justificativa para a intervenção federal no estado e a decretação do Estado Novo. Mas antes é preciso esclarecer que não se trata aqui de simplesmente associar essas práticas políticas ao discurso dos intelectuais, como se aquelas fossem um mero reflexo deste. O que se pretende, como já foi dito, é demonstrar como as interferências mútuas entre os campos político e intelectual contribuíram para legitimar um regime supostamente baseado em nossa própria realidade e em princípios tecnocráticos, acima das faç̧ões políticas. Vejamos, então, de que maneira essas questões podem ser percebidas no jogo político gaúcho.

De um modo geral, a historiografia sobre esse período (cf., p. ex., PESAVENTO, 1980; TRINDADE, 1980) destaca as oscilações 
nas relações entre a Frente Única Gaúcha (FUG) e o Partido Republicano Liberal (PRL) ${ }^{8}$ e seus fortes conflitos, seja no plano interno ou em suas relações com o governo federal. Até fins de 1935, pode-se dizer que o PRL exerceu o controle hegemônico do poder regional e, em âmbito nacional, constituía a principal base de apoio político a Vargas na Câmara dos Deputados, enquanto a FUG manteve-se na oposição. No ano seguinte, contudo, o antagonismo de ambos à Lei de Segurança Nacional (LSN) ${ }^{9}$ levou-os a negociar um modus vivendi regional, em nome das liberdades civis e da autonomia dos estados. A princípio, essa aproximação permitiu também à FUG acalentar o sonho de voltar a ocupar o poder político regional e a Flores da Cunha, que comandava autocraticamente o PRL, a ambição de fortalecer seu poder regional e projetar-se nacionalmente à sucessão de Vargas.

Após meses de intensas negociações e muitas idas e vindas, a FUG e o PRL assinaram um acordo, conhecido como Fórmula Pilla $^{10}$, que estabelecia a divisão do poder político regional entre seus próceres: Raul Pilla e Lindolfo Collor (FUG) assumiram, respec-

8 A Frente Única Gaúcha (FUG) foi formada em 1928, durante o governo de Getúlio Vargas no Rio Grande do Sul, pela união do Partido Republicano Rio-Grandense (PRR) com o Partido Libertador (PL). Participou ativamente da Revolução de 1930, constituindo-se em uma de suas principais forças. Durante a Revolução Constitucionalista (1932), porém, suas lideranças dividiram-se entre os que se mantiveram fiéis a Vargas e os que se aliaram aos paulistas. Os primeiros, liderados por Flores da Cunha, formaram um novo partido político - o Partido Republicano Liberal (PRL) -, enquanto os últimos mantiveram-se em seus partidos tradicionais e aliados em Frente Única até a extinção dos partidos políticos pelo Estado Novo, em 1937.

9 A LSN foi aprovada pelo Congresso Nacional em 4 de abril de 1935, em nome da ordem e da estabilidade política do país, como forma de combater o que o governo dizia ser "a ameaça do comunismo". Após a Intentona Comunista, em novembro daquele mesmo ano, as medidas repressivas autorizadas pela LSN, que restringiam a autonomia dos estados, foram aplicadas indistintamente em todo o país, o que gerou descontentamentos entre as elites políticas gaúchas.

10 A Fórmula Pilla, de teor nitidamente parlamentarista, foi um acordo assinado entre o PRL e a FUG em 9 de janeiro de 1936, com o objetivo de conciliar as forças políticas regionais, divididas desde 1932. Entre outros aspectos, definia o seguinte: 1) o Governador do Estado nomeará um Presidente do Secretariado, que deverá comparecer regularmente à Assembléia Legislativa para prestar contas das ações do governo; 2) se houver desinteligência entre o Governador e um de seus secretários, o caso deverá ser submetido ao Gabinete, que o decidirá; 3) os secretários serão escolhidos entre os nomes indicados pelas direções dos partidos. Esse acordo, porém, teve uma duração bastante efêmera e tumultuada, tendo sido rompido em outubro de 1936. 
tivamente, as secretarias da Fazenda e da Agricultura, enquanto Darcy Azambuja (PRL) foi nomeado Presidente do Secretariado pelo Governador Flores da Cunha, em um surpreendente arranjo de inspiração parlamentarista. Porém, contrariando as expectativas, esse modus vivendi provocou, desde o início, fortes manifestações de descontentamento entre políticos de ambos os grupos, além de questionamentos acerca de sua constitucionalidade. Loureiro da Silva (PRL), por exemplo, dizia: "O pobre do Flores perdeu a confiança dos seus companheiros, que apenas obedecem por questão de deferência pessoal, mas que na primeira oportunidade tirarão a diferença, visto que ele não está à altura de dirigir uma grande agremiação partidária [...]" (GV 36.01.28/2 XXI-29b).

De parte da FUG, seus representantes viram-se frustrados em suas expectativas de poder, acusando Flores da Cunha de desrespeitar os termos parlamentares do acordo e de governar autoritariamente. Este, por sua vez, dizia-se traído por seus novos aliados, que nem sempre referendavam suas decisões e projetos de governo durante as votações na Assembléia Legislativa. Por outro lado, deve-se ainda fazer referência à posição do governo federal, que, desafiado em seu poder pelo modus vivendi gaúcho, procurou, desde o início, inviabilizálo, utilizando-se, para isso, de duas estratégias fundamentais: 1) promover uma dissidência interna no PRL, por meio da ação dos deputados Loureiro da Silva e Benjamin Vargas ${ }^{11}$, com o objetivo de enfraquecer o poder regional de Flores da Cunha; 2) atrair para si o apoio da FUG, por meio da oferta de cargos e favores e da ne-

$11 \mathrm{O}$ apoio de Flores da Cunha à candidatura de Armando de Sales Oliveira à Presidência - pela defesa deste ao federalismo - acirrou os antagonismos entre o Governador gaúcho e Getúlio Vargas, que oficialmente apoiava o nome de José Américo de Almeida. Por intermédio dos deputados Loureiro da Silva e Benjamin Vargas, Getúlio passou a estimular, no plano regional, as divergências entre os próprios partidários do Governador, que estavam descontentes com o modus vivendi celebrado com a FUG. No plano federal, Vargas procurou atrair o apoio dessa Frente Única oferecendo cargos e favores políticos e negociando um acordo político nacional, que ficou conhecido como "octólogo", devido ao número de suas cláusulas. Esse acordo, cujo objetivo principal era a indicação de um nome de consenso à sucessão presidencial, indicava o próprio Vargas como mediador de sua sucessão, o que levou ao seu total rompimento com Flores da Cunha e também do próprio modus vivendi regional entre o PRL e a FUG. Entretanto, com a instituição do Estado Novo, o octólogo nunca chegou a vigorar. 
gociação de uma espécie de modus vivendi nacional. Esse conjunto de divergências e ações acabou por levar ao rompimento definitivo do acordo político gaúcho em outubro de 1936.

Face ao exposto, pode-se dizer que o modus vivendi celebrado em nome da liberdade e da autonomia estadual constituiu, na realidade, uma alternativa de poder à FUG e ao PRL, de acordo com as pretensões próprias de cada partido. Já a ação do governo federal, que supostamente visava à união nacional, na verdade tinha por objetivo provocar a cisão e o acirramento dos conflitos regionais, conforme suas próprias pretensões autoritárias de poder.

Diante dos fatos, a reação de Flores da Cunha foi tentar fortalecer-se militarmente e recompor a antiga política dos estados ${ }^{12}$, como forma de combater a oposição e garantir a autonomia regional contra uma possível intervenção federal. Cada vez mais se avolumavam as denúncias das arbitrariedades cometidas pelo Governador, que incluíam desde o assassinato de seus opositores e ameaças aos deputados até a formação de corpos provisórios - disfarçados de trabalhadores rodoviários - e a existência de inúmeros depósitos de material bélico disseminados pelo estado.

Tais atitudes, porém, em vez de fortalecerem o poder de Flores da Cunha, forneceram aos seus opositores e aos militares os argumentos necessários para estes solicitarem a intervenção federal no Rio Grande do Sul, em benefício de uma suposta união nacional. Nesse contexto, reconhecendo a "esterilidade de sua ação legislativa", como diria Oliveira Vianna, os próprios deputados gaúchos pediram, em telegrama enviado a Getúlio Vargas, "a transferência da execução do estado de guerra, no Rio Grande do Sul, a uma pessoa alheia à presente contenda política e da imediata e direta confiança de V. Exa. [...]" (Correio do Povo, 29.abr.1937, p. 1). Pode-se dizer, portanto, que o governo federal e a própria oposição regional utilizaram-se pragmaticamente do discurso intelectual do realismo político e da neutralidade do Estado contra o facciosismo dos partidos, a fim de legitimar o autoritarismo que ora se implantava com o Estado Novo.

12 Em seu esforço de oposição à política centralista de Vargas, Flores da Cunha buscou o apoio dos estados de São Paulo, Bahia e Pernambuco, visando fortalecer novamente as políticas estaduais em defesa da autonomia regional. 
Esses mesmos argumentos serão utilizados ao longo de todo o período do regime para justificar, por exemplo, a indicação, pelo Presidente, de militares estranhos às elites políticas regionais para a Interventoria gaúcha. A esse respeito, Oliveira Vianna dizia que a União, em sua relação com os estados, teria assegurado seu direito de intervenção e de subordinação das políticas estaduais aos seus interesses. Isso porque, em oposição ao antigo primado do parlamento vigente nos regimes anteriores - cuja marca seria o facciosismo dos partidos -, o Estado Novo definir-se-ia pelo primado do Executivo, cuja peça mais importante seria o Presidente da República. Segundo Oliveira Vianna, essa nova lógica política não estaria simplesmente baseada em uma ideologia antidemocrática, mas fundada em nossa experiência anterior, quando a Câmara havia se tornado "o encontro dos politicalhos mais graduados dos estados" (VIANNA, 1939, p. 146). Desse modo, afirma não ser muito adequado empregar a expressão "Estado autoritário" para referir-se ao Estado Novo, por haver nessa denominação um certo pleonasmo, "porque o conceito de Estado implica, de si mesmo, a idéia de autoridade. O que se instituiu foi a democracia autoritária, isto é, a democracia fundada na autoridade e não mais na liberdade, como princípio essencial" (idem, p. 149-152). Nesse mesmo sentido, seria justificada também a extinção dos partidos como um "ato do mais puro realismo político" (idem, p. 195), em nome da unidade nacional e do princípio de autoridade.

No caso do Rio Grande do Sul, onde houve forte resistência ao centralismo de Vargas, pode-se dizer que os princípios de autoridade acima referidos - a intervenção federal e o primado do Executivo começaram a valer antes mesmo de novembro de 1937.

Nesse caso, já em maio daquele ano, o governo federal havia determinado a transferência da execução do estado de sítio para as mãos do Comandante da III Região Militar ${ }^{13}$, o que limitou de fato

13 Em maio de 1937, o Comandante da III Região Militar era o General Lúcio Esteves, o qual, por suspeita de conivência ou inépcia diante das articulações de Flores da Cunha contra o governo federal, foi substituído em agosto daquele ano pelo General Daltro Filho, que assumiu também a execução do estado de guerra no Rio Grande do Sul e, em novembro de 1937, foi nomeado o primeiro Interventor Federal do Estado. 
e de direito os poderes do ainda Governador Flores da Cunha ${ }^{14}$. A esse respeito, apoiando-se no discurso da neutralidade do Estado, o General Daltro Filho proclamava à nação a importância de que o Exército, a fim de manter a ordem e a unidade nacional, "possa pairar acima das paixões em convulsão" (Correio do Povo, 1.ago.1937, p. 1). Porém, de acordo com João Carlos Machado - líder do PRL - "ao contrário do que preceituou em sua proclamação, era precisamente a política partidária que estava inspirando ao Exército, pelo menos no caso do Rio Grande" (Correio do Povo, 7.ago.1937, p. 1).

De fato, o líder liberal não deixava de ter razão em sua manifestação, que consistia em uma espécie de denúncia do caráter partidário da intervenção federal, que, mais uma vez, utilizava-se de maneira pragmática do discurso intelectual da neutralidade contra o espírito de facção. Afinal, tal intervenção do Exército ocorrera por solicitação dos próprios deputados da FUG e a mando de Getúlio Vargas, nesse momento, aliados contra a ameaça que Flores da Cunha representava aos ideais políticos de ambos. Aliás, esse caráter político (e mesmo partidário) da intervenção ficará ainda mais claro ao se observarem as novas formas de organização e condução do governo gaúcho pelos interventores militares durante o Estado Novo.

Em princípio, o poder dos interventores seria justificado pelo direito de intervenção do governo federal - do qual eles eram os representantes - e pelo primado do Executivo, em substituição ao princípio liberal-democrático da divisão de poderes. Na prática política, porém, em momento algum a ação dos interventores esteve livre de toda e qualquer pressão política, pois eles situavam-se "a meio caminho entre a identidade e a independência face aos grupos dominantes estaduais" (SOUZA, 1976, p. 89). Ou seja, em vez de "pairar acima das paixões", coube aos interventores a tarefa de negociar e procurar conciliar os diferentes interesses partidários regionais. De outra forma, pode-se dizer que a imposição e a manutenção da ordem política regional e nacional durante o Estado Novo não se deu pela eliminação dos conflitos partidários, mas

14 Flores da Cunha renunciou ao governo em $1^{\text {o }}$ de outubro de 1937 , em manifesto intitulado Ao Rio Grande do Sul. 
pela repressão, cooptação e conciliação de seus interesses aos do novo regime, conforme fosse o caso.

Se aos partidários de Flores da Cunha coube a mais dura repressão e o exílio, restou a necessidade de os interventores cooptarem os dissidentes do PRL e conciliarem os interesses de poder da FUG aos princípios do regime. Tal condição foi logo percebida pelo Interventor Daltro Filho, que, após substituir 42 intendentes municipais e enfrentar fortes protestos, afirmou não ter liberdade para substituir um prefeito ou mesmo um delegado "sem levantar clamores intensos, extensos e vivamente impressionadores" (GV 37.11.06/2 XXVIII-2b). A esse respeito, Protásio Vargas defendia a adoção, pelo governo, de uma política de apaziguamento entre os partidos, embora admitisse como legítima a pretensão da FUG de adotar "essa antipática medida" de substituição dos prefeitos, "por seu interesse partidário" (GV 37.12.05 XXVIII-76).

Desse modo, por pressão das forças partidárias regionais, foi criada no Rio Grande do Sul a Comissão Mista, que tinha por objetivo dividir o poder municipal conforme a força política de cada um dos partidos, ou seja, nos municípios em que o PRL fosse majoritário, as prefeituras deveriam ser ocupadas por representantes da dissidência liberal; naqueles em que a FUG constituísse a maioria, as prefeituras caberiam ao PRR ou ao PL. Portanto, como disse Protásio Vargas em carta ao seu irmão Getúlio: no Rio Grande do Sul, "não há partidos políticos, porém existe política de partidos” (GV 38.04.26/2 XXIX-62). E foi essa política de partidos que pautou a ação dos interventores e as relações políticas regionais e nacionais durante todo o período de vigência do Estado Novo.

Nesse sentido, deve-se observar que essas mesmas relações partidárias mantiveram-se inclusive após a instalação do Departamento Administrativo do Serviço Público (DASP) ${ }^{15}$, que, no Rio

15 A Constituição de 1937, em seu artigo 67, já previa a criação de um departamento administrativo que substituísse as antigas assembléias legislativas, então extintas, com o objetivo de modernizar a administração pública e elaborar seu orçamento. Sua criação efetiva, porém, ocorreu somente em 1938, por meio do Decreto-Lei n. 579 , de 30 de julho. Em nível regional, a regulamentação dos departamentos administrativos estaduais ocorreu em 1939, com o Decreto n. 1.202, também conhecido como Código dos Interventores. 
Grande do Sul, foi implantado em 1939, durante o governo de Cordeiro de Farias. Esse Departamento, segundo Getúlio Vargas, foi criado com o objetivo de ser um órgão técnico, em oposição "aos inconvenientes das assembléias exclusivamente políticas, o Poder Legislativo", que teria se mostrado inoperante por seu facciosismo partidário em detrimento dos interesses públicos. Ou seja, o DASP deveria constituir-se em um órgão insulado burocraticamente ${ }^{16}$ e pautado pelo universalismo de procedimentos ${ }^{17}$, mas, como bem define Edson Nunes, o insulamento burocrático não é um processo técnico e apolítico, podendo-se perceber diferentes graus de insulamento e mesmo o desinsulamento de algumas instituições (NUNES, 1997, p. 34). No caso do DASP, este acabou por se constituir em um organismo paradoxal, combinando seu caráter técnico à missão de "conceber e analisar criticamente o regime autoritário” (idem, p. 54).

De acordo com os princípios do universalismo de procedimentos, que estariam em consonância com o discurso intelectual da neutralidade do Estado, o DASP passou a adotar algumas medidas, como, por exemplo: a instituição de concurso para a seleção de funcionários públicos; a elaboração do estatuto do funcionalismo público civil; a padronização de materiais de expediente e de procedimentos administrativos; a definição de critérios técnicos para a elaboração do orçamento da União e dos Estados etc. A respeito de tais medidas, pode-se citar a ampla divulgação, na imprensa, de um concurso para escriturário, que o DASP dizia ser o maior concurso público realizado até então, com provas simultâneas nas cidades de Belém, Recife, Salvador, Rio de Janeiro, Belo Horizonte, São Paulo e Porto Alegre, envolvendo um total de 3 mil candidatos (Correio do Povo, 1.set.1940, p. 15). Porém, essas medidas não foram capazes ou não tiveram a intenção de eliminar por completo da

16 Segundo Edson Nunes (1997, p. 34), o insulamento burocrático está ligado à criação de ilhas de racionalidade e especialização técnica na administração pública, com "a redução do escopo da arena em que os interesses e demandas populares podem desempenhar um papel. Esta redução da arena é efetivada pela retirada de organizações cruciais do conjunto da burocracia tradicional e do escopo político governado pelo Congresso e pelos partidos políticos [...]".

17 Edson Nunes (1997, p. 23) defendia que o universalismo de procedimentos são normas que "podem ser formalmente utilizadas por todos os indivíduos da polity, ou a eles aplicadas [...]". 
administração pública brasileira a figura do funcionário extranumerário, cuja contratação devia-se aos favoritismos políticos ou pessoais e era mantida fora do sistema de mérito. Segundo Vieira da Cunha (1963, p. 100), essa "falsa separação entre funcionários e extranumerários" tornava-se "cada vez mais insustentável”, sendo estes últimos inclusive mais numerosos que os primeiros.

Já em relação à prática política do regime, tal como vimos ter ocorrido no caso dos interventores, também ao DASP coube o papel de cooptar os diferentes interesses políticos e partidários e conciliá-los aos do Estado Novo. No caso gaúcho, essa situação pode ser exemplificada pela própria composição do Departamento Administrativo do Estado, que, em lugar de técnicos, foi composto de representantes de cada uma das antigas correntes partidárias gaúchas - PRL, PRR e PL: José Acioli Peixoto, ex-integrante do Tribunal de Contas do Estado durante o governo de Flores da Cunha; Moysés Vellinho, dissidente do PRL; Alberto Pasqualini, vereador de Porto Alegre pelo PL e, em 1943, Secretário do Interior de Ernesto Dorneles; Carlos Eurico Gomes, ex-Superintendente de Saúde e Higiene do Distrito Federal; Camilo Teixeira Mércio, Deputado Federal pelo PRL; Gaston Englert, ex-Presidente do Banco do Estado do Rio Grande do Sul (Banrisul) durante o governo de Getúlio Vargas no Rio Grande do Sul, e Olivério de Deus Vianna, prócer do PRR ${ }^{18}$.

A esse respeito, ainda que não se tenha a intenção de avançar na análise da atuação do Departamento Administrativo do Estado (cf. CAMARGO, 1983), pode-se dizer que os critérios políticos que pautaram sua composição poderiam ser um indicativo de seu caráter complementar em relação às interventorias. Dado seu caráter paradoxal, como definiu Nunes, pode-se sugerir que a ação do DASP, supostamente pautada por critérios técnicos, legitimou a ação política dos interventores, contribuindo também para a cooptação das diferentes forças partidárias regionais e conciliação de seus interesses.

Por fim, pode-se dizer que os breves exemplos citados sobre o caso dos interventores e do Departamento Administrativo do Estado do Rio Grande do Sul talvez não representem exemplos isolados

18 Essa era a composição do Departamento Administrativo do Estado quando de sua criação, em julho de 1939. 
de como as forças políticas regionais relacionaram-se com o novo regime, nem do modo como ocorreram as mútuas e pragmáticas interferências entre os campos intelectual e político durante o Estado Novo, conforme se procurou demonstrar ao longo deste texto.

Recebido em 10.2.2008

Aprovado em 15.4.2008

\section{Referências bibliográficas}

ABREU, L. A. Um olhar regional sobre o Estado Novo. Porto Alegre: PUC-RS, 2007.

BRESCIANI, M. S. O charme da ciência e a sedução da objetividade: Oliveira Vianna entre os intérpretes do Brasil. São Paulo: UNESP, 2005.

CAMARGO, D. D'O. Centralização e intervenção: padrão político e institucional do Estado Novo no Rio Grande do Sul - o Conselho Administrativo do Estado. Porto Alegre. Dissertação (Mestrado em Ciência Política). Universidade Federal do Rio Grande do Sul, 1983.

CAMPOS, F. O Estado nacional. Brasília: Senado Federal, 2001.

CUNHA, M. W. V. O sistema administrativo brasileiro. Rio de Janeiro: CEBRAPE, 1963.

LAMOUNIER, B. A formação de um pensamento político autoritário na Primeira República: uma interpretação. In: FAUSTO, B. (org.). História geral da civilização brasileira. T. III: O Brasil republicano. V. 2: Sociedade e instituições. 5ª ed. São Paulo: Difel, 1985.

NUNES, E. A gramática política do Brasil: clientelismo e insulamento burocrático. Rio de Janeiro: J. Zahar, 1997.

ODÁLIA, N. As formas do mesmo: ensaios sobre o pensamento historiográfico de Varnhagen e Oliveira Vianna. São Paulo: UNESP, 1997.

PECAULT, D. Os intelectuais e a política no Brasil. Entre o povo e a nação. São Paulo: Ática, 1990.

PESAVENTO, S. Economia e poder nos anos 30. Porto Alegre: Mercado Aberto, 1980. 
SOUZA, M. C. C. Estado e partidos políticos no Brasil (1930-1964). São Paulo: Alfa-Ômega, 1976.

TORRES, A. A organização nacional. São Paulo: Nacional, 1978.

TRINDADE, H. Poder Legislativo e autoritarismo no Rio Grande do Sul (1891-1937). Porto Alegre: Sulina, 1980.

VIANNA, O. O idealismo na evolução política do Império e da República. São Paulo: Biblioteca d'O Estado de São Paulo, 1922. . Problemas de política objetiva. São Paulo: Companhia Editora Nacional, 1930. . O idealismo da Constituição. São Paulo: Nacional, 1939. . Populações meridionais do Brasil. Rio de Janeiro: J. Olympio, 1952 (1920).

\section{Fontes Documentais}

Arquivo Getúlio Vargas. Rio de Janeiro: Fundação Getúlio Vargas.

Correio do Povo. Porto Alegre, 1937-1945. 